\title{
Evaluation of the Phenolic Profile, Mineral, and Fatty Acid Content and Antioxidant Activity of Black Cumin before and after an In Vitro Simulated Gastrointestinal Digestion ${ }^{\dagger}$
}

\author{
Johura Ansary (1)
}

check for updates

Citation: Ansary, J. Evaluation of the Phenolic Profile, Mineral, and Fatty Acid Content and Antioxidant Activity of Black Cumin before and after an In Vitro Simulated Gastrointestinal Digestion. Med. Sci. Forum 2020, 2, 9. https://doi.org/ 10.3390/CAHD2020-08638

Published: 1 December 2020

Publisher's Note: MDPI stays neutral with regard to jurisdictional claims in published maps and institutional affiliations.

Copyright: (C) 2020 by the author. Licensee MDPI, Basel, Switzerland. This article is an open access article distributed under the terms and conditions of the Creative Commons Attribution (CC BY) license (https:// creativecommons.org/licenses/by/ $4.0 /)$.

\begin{abstract}
Dipartimento di Scienze Cliniche Specialistiche ed Odontostomatologiche, Facoltà di Medicina, Università Politecnica delle Marche, 60131 Ancona, Italy; nubansary@gmail.com

+ Presented at the 1st International E-Conference on Antioxidants in Health and Disease, 1-15 December 2020; Available online: https://cahd2020.sciforum.net/.
\end{abstract}

\begin{abstract}
Black cumin (N. sativa; Ranunculaceae family) is well known for its numerous beneficial biological effects, while its seed extracts exhibit anti-diabetic, anti-cancer, immunomodulatory, antimicrobial, anti-inflammatory, anti-hypertensive and antioxidant activities [1,2]. This study aimed to evaluate the phenolic and mineral contents, chemical composition and antioxidant activity of methanolic extracts from dried black cumin seed powder. In addition, we evaluated, after gastrointestinal digestion, the effect of phenolic components and their antioxidant activity by utilising an in vitro gastrointestinal digestion process. Black cumin showed high amounts of total phenolic and flavonoid contents (such as dihydroxybenzoic acid and ferulic acid) via HPLC analysis. Six mineral elements (Ca, Cu, Fe, K, Se and $\mathrm{Zn}$ ) were determined by using coupled plasma mass spectrometry. Twenty-five (25) fatty acids (13 saturated, 7 unsaturated and 5 unsaturated omega fatty acids) were identified by gas chromatography, with linoleic acid being the most abundant. In addition, black cumin methanolic extract presented higher antioxidant capacity measured by DPPH, FRAP and TEAC. Finally, dried black cumin powder was evaluated after gastrointestinal digestion, with results indicating that phenolics, flavonoids and antioxidant capacity increased in the gastric fraction (1.81-, 1.03- and 2.1-fold, respectively) compared with the undigested methanolic extract. Moreover, a higher amount of total phenolic and flavonoid content, as well as a higher total antioxidant capacity were found present in the gastric and elimination fraction than in the bio-accessible fraction (that represent the colon availability). Our results demonstrate a significant reduction in the quantity of phenolic $(68 \%)$ and flavonoid (95.53\%) compounds after gastrointestinal digestion in the bio-accessible fraction, together with a decrease in total antioxidant activity, suggesting that phenolic compounds are responsible for the observed antioxidant activity.
\end{abstract}

Keywords: black cumin; polyphenols; mineral content; fatty acid profile; antioxidant and gastrointestinal digestion

Supplementary Materials: The following are available online at https:/ /www.mdpi.com/article/10 .3390/CAHD2020-08638/s1.

Institutional Review Board Statement: Not applicable.

Informed Consent Statement: Not applicable.

Data Availability Statement: https://www.mdpi.com/ethics. 


\section{References}

1. Gilani, A.H.; Jabeen, Q.; Khan, M.A. A review of medicinal uses and pharmacological activities of Nigella sativa. Pak. J. Biol. Sci. 2004, 7, 441-4455. [CrossRef]

2. Kooti, W.; Hasanzadeh-Noohi, Z.; Sharafi-Ahvazi, N.; Asadi-Samani, M.; Ashtary-Larky, D. Phytochemistry, pharmacology, and therapeutic uses of black seed (Nigella sativa). Chin. J. Nat. Med. 2016, 14, 732-745. [CrossRef] 